\section{Regulation of Polar Auxin Transport by AtPIN1 in Arabidopsis Vascular Tissue}

\author{
Leo Gälweiler, Changhui Guan, Andreas Müller, Ellen Wisman, \\ Kurt Mendgen, Alexander Yephremov, Klaus Palme*
}

Polar auxin transport controls multiple developmental processes in plants, including the formation of vascular tissue. Mutations affecting the PIN-FORMED (PIN1) gene diminish polar auxin transport in Arabidopsis thaliana inflorescence axes. The AtPIN1 gene was found to encode a 67-kilodalton protein with similarity to bacterial and eukaryotic carrier proteins, and the AtPIN1 protein was detected at the basal end of auxin transport-competent cells in vascular tissue. AtPIN1 may act as a transmembrane component of the auxin efflux carrier.

Charles Darwin had proposed the concept of translocated chemical messengers in higher plants, which finally resulted in the discovery of polar auxin transport in the 1930s (1). The transport of auxin from the plant tip downward provides directional information, influencing vascular tissue differentiation, apical development, organ regeneration, tropic growth, and cell elongation $(2,3)$. Polar auxin transport can be monitored by following the movement of radiolabeled auxin through tissues. Auxin transport is specific for the major auxin indoleacetic acid and various synthetic auxins, it requires energy, and it occurs with a velocity of 7 to $15 \mathrm{~mm} /$ hour (2). This transport can be specifically inhibited by synthetic compounds, known as polar auxin transport inhibitors, and by naturally occurring flavonoids (4). The current concept,

L. Gälweiler, C. Guan, A. Müller, and K. Palme are at the Max-Delbrück-Laboratorium in der Max-PlanckGesellschaft, Carl-von-Linné-Weg 10, D-50829 Köln, Germany. E. Wisman and A. Yephremov are at the Max-Planck-Institut für Züchtungsforschung, Abteilung Molekulare Pflanzengenetik, Carl-von-Linné-Weg 10, D-50829 Köln, Germany. K. Mendgen is at the Universität Konstanz, Fakultät für Biologie/Phytopathologie, D-78457 Konstanz, Germany.

*To whom correspondence should be addressed. Email: palme@mpiz-koeln.mpg.de known as the "chemiosmotic hypothesis," proposes that (i) the driving force for polar auxin transport is provided by the transmembrane proton motive force, and that (ii) the

Fig. 1. Phenotypic and Southern blot analysis of the transposon insertional mutant Atpin 1::En134. (A) The most obvious phenotypic aspect of the homozygous mutant represents the naked, pinforming inflorescence with no or just a few defective flowers. (B) Atpin 1::En134 seedlings showed frequently aberrant cotyledon positioning or triple cotyledons. (C) A mutant cauline leaf exhibited abnormal vein branching resulting in the appearance of fused twin or triple leaves. Unusually, the leaf and "pin"-forming axillary shoot have formed in opposite positions. (D) Drastically fasciated inflorescence of an aged mutant. (E) Southern blot analysis of a segregating Atpin 1::En134 mutant population. The $\mathrm{M}_{2}$ progeny of the heterozygous Atpin $1::$ En134 mutant showed 3:1 segregation for wild-type and mutant phenotype plants (8). The cetyltrimethylammonium bromide method (23) was used to isolate genomic DNA from plants showing the mutant $(22,27,2528)$ and wild-type $(12,43,45,46$, $47,52,56,60,75,78,79)$ phenotype and from ecotype Columbia (Col) plants lacking En-1 insertions. After Xba I digestion, the DNA was separated on a $0.8 \%$ agarose gel ( $2 \mu \mathrm{g}$ per lane), transferred to a Nylon membrane and hybridized with a ${ }^{32}$ p-labeled 3 '-end probe of the En-1 transposon (24). Only one fragment of $2.3 \mathrm{~kb}$ in length (marked by an arrow) was commonly detected in all 12 tested homozygous Atpin 1::En134 mutants and in 15 heterozygous plants (not all are shown), indicating cosegregation with the Atpin 1::En134 allele. Size bars represent 25 $\mathrm{mm}(\mathrm{A}), 2.5 \mathrm{~mm}(\mathrm{~B})$, and $10 \mathrm{~mm}[(\mathrm{C})$ and (D)]. 
and abnormalities in the number, size, shape, and position of lateral organs (Fig. 1, A to D), similar to those described for the pin-formed mutant $(6,7)$. In crosses between heterozygous pin-formed and Atpin1::En134 mutants, 25\% of the $\mathrm{F}_{1}$ progeny showed the mutant phenotype, indicating that these mutations were alleles of the same gene (9). Further analysis showed that Atpin1::En111 and Atpin1::En349 were also allelic to Atpin1::En134 (Fig. 2A) (10).

The AtPIN1 gene. To identify the En-1 transposon insertion responsible for the mutant phenotype, we performed Southern (DNA) blot analysis with the $\mathrm{M}_{2}$ progeny of a heterozygous Atpin1::En134 mutant. An En-1 probe corresponding to the $3^{\prime}$ end of the transposon detected a single 2.3-kb fragment of Xba I-digested genomic DNA cosegregating with plants showing the mutant phenotype. This fragment was also detected in het-

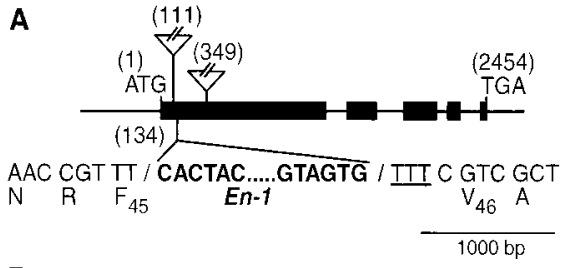

B

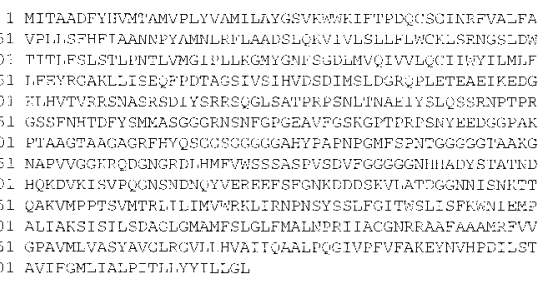

C

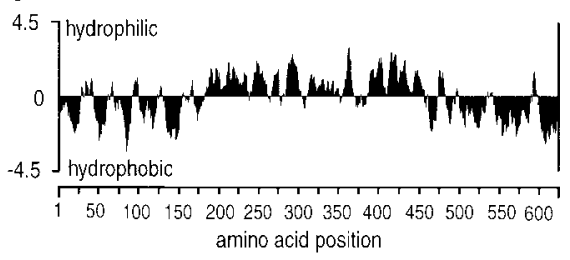

Fig. 2. Structural analysis of AtPIN1 alleles and of the deduced AtPIN1 amino acid sequence. (A) Structure of the AtPIN1 gene (drawn to scale), with black boxes representing exons and mapped $E n-1$ insertion sites in the independent mutant alleles Atpin1::En111 (111), Atpin1::En134 (134), and Atpin1::En349 (349). Numbers in brackets show base pair positions. The positions of the translational start (ATG) and termination codons (TGA) of the predicted open reading frame are depicted. Nucleotide sequences flanking both ends of the En-1 transposon in Atpin1::En134 show the disruption of the coding sequence at codon $45(F)$. The duplication of nucleotide triplets (TTT) is characteristic for $E n-1$ insertion sites (25). (B) Amino acid sequence (26) deduced from the AtPIN1 cDNA (accession number AF089084). (C) Hydropathy analysis of AtPIN1. The hydropathy plot was generated with the Lasergene software (DNAstar, Madison, Wisconsin) and the method of Kyte and Doolittle with a window size of nine amino acids (27). erozygous plants, which segregated the mutant phenotype in about $25 \%$ of their $\mathrm{M}_{3}$ progeny, as expected for a recessive mutation (Fig. 1E). DNA flanking the tagged locus was isolated from the genomic DNA of homozygous Atpin1::En134 mutant plants with the use of a ligation-mediated polymerase chain reaction (PCR). The resulting PCR fragment was sequenced and used as a probe to isolate homologous clones from wild-type Arabidopsis genomic and complementary DNA (cDNA) libraries (11). DNA sequence analysis revealed that the AtPIN1 gene consisted of five exons with lengths of 1246, 235, 244, 77, and 64 nucleotides (Fig. 2A). Analysis of mutant Atpin1 transposon insertional alleles showed that the En-1 element was inserted into the first exon of the AtPIN1 gene (Fig. 2A). Excision of the En-1 transposon from the Atpin $1::$ En134 and Atpin1::En349 alleles resulted in revertant alleles that restored the wild-type phenotype. Sequence analysis of the revertant alleles confirmed that the En- 1 element had excised from the first AtPIN1 exon, resulting in an exact restoration of the AtPIN1 open reading frame (9).

Northern (RNA) blot hybridizations with an AtPIN1-specific probe showed that the gene was transcribed in all wild-type organs tested, yielding a transcript signal of $2.3 \mathrm{~kb}$ in length (Fig. 3A). AtPIN1 gene expression was absent in the homozygous transposon insertional mutants Atpin1::En134 (Fig. 3B, lane 2) and Atpin1::En349 (Fig. 3B, lane 5). Heterozygous plants (Fig. 3B, lanes 1, 4, and 6) showed AtPIN1 expression, probably from their wild-type allele. Similarly, homozygous pin-formed mutants did not express AtPIN1 (Fig. 3A, lane 3). We used an AtPIN1 cDNA probe to identify a yeast artificial chromosome (YAC) contig from the CIC YAC library that represented a region between centimorgan 92.7 and 113.6 in chromosome 1 of Arabidopsis similar to the location of the PIN-FORMED locus $(7,12)$. These data from genetic analysis, physical mapping, and gene

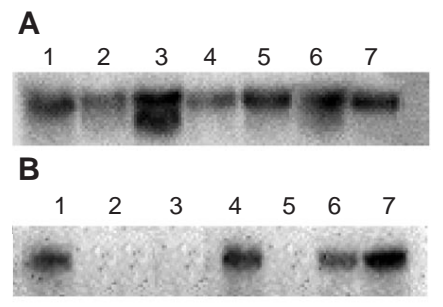

Fig. 3. AtPIN1 gene expression analysis. (A and B) Northern blot analysis. Total RNA from different organs and plants were isolated and northern blot analysis was performed (15 $\mu g$ of total RNA per lane) with a ${ }^{32} \mathrm{P}$-radiolabeled AtPIN1 (base pairs 602 to 1099) probe (28). In (A) various $A$. thaliana ecotype Columbia organs were analyzed: cotyledons (lane 1), flowers (lane 2), roots (lane $3)$, rosette leaves (lane 4), seedlings (lane 5), inflorescence axes (lane 6), and siliques (lane 7). In (B) different allelic Atpin 1 mutants were analyzed: heterozygous Atpin 1::En134 (lane 1), homozygous Atpin 1::En134 (lane 2), homozygous pin-formed (lane 3), heterozygous pin-formed (lane 4), homozygous Atpin 1::En349 (lane 5), heterozygous Atpin 1::En349 (lane 6), and wild-type Columbia (lane 7). The RNA was prepared from inflorescence axes of each genotype. ( $\mathbf{C}$ to $\mathbf{E}$ ) In situ hybridization analysis of the AtPIN1 gene expression in wild-type inflorescence axes. Stem segments of plants

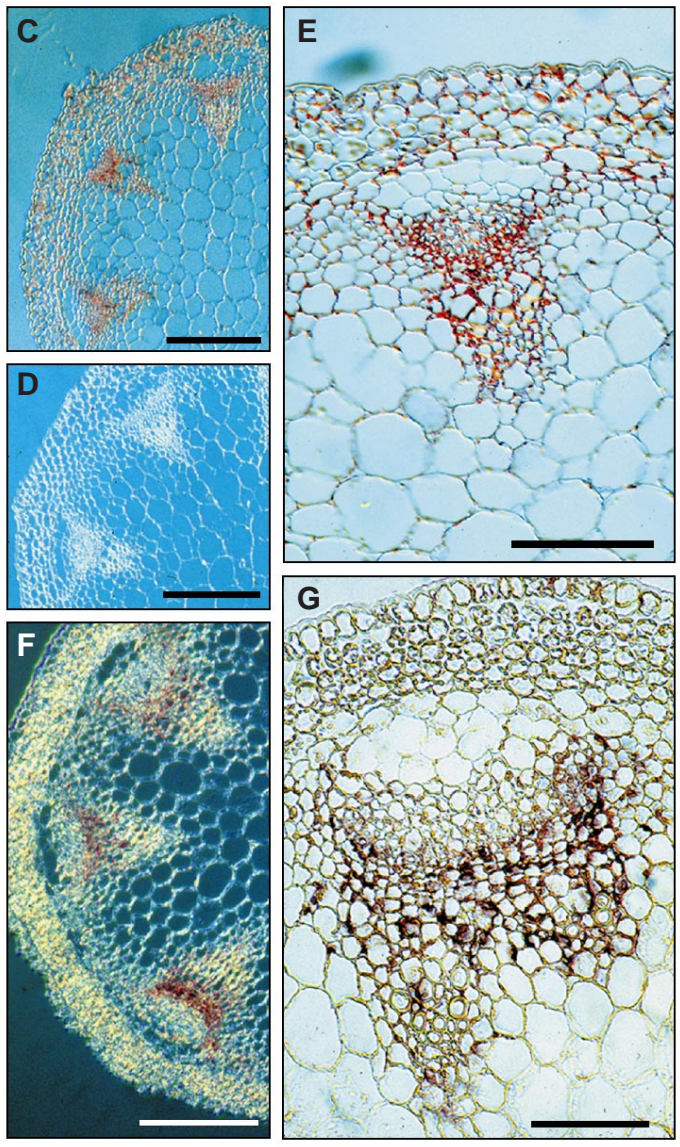
were fixed, paraffin embedded, cross sectioned $(8 \mu \mathrm{m})$, and probed with either antisense $[(C)$ and $(E)]$ or sense (D), digoxigenin-labeled, in vitro-transcribed AtPIN1 RNA. The AtPIN1 transcript signals were indirectly visualized with the help of alkaline phosphatase-conjugated secondary antibodies (29). (E) is a magnified section of a vascular bundle of (C). AtPIN1-specific staining (red) is localized in cambial and xylem tissues. (F and $\mathbf{G}$ ) Immunocytochemical localization of AtPIN1 protein in cross sections of inflorescence axes. Stem segments of wild-type plants were fixed, paraffin embedded, sectioned ( $8 \mu \mathrm{m})$, and incubated with affinity-purified polyclonal anti-AtPIN1. Bound anti-AtPIN1 was visualized with the help of alkaline phosphatase-conjugated secondary antibodies $(18,30)$. AtPIN1-specific staining (purple) was found in cambial and in young and parenchymatous xylem cells (G). Size bars represent 100 $\mu \mathrm{m}[(\mathrm{E})$ and $(\mathrm{G})]$ and $200 \mu \mathrm{m}[(\mathrm{C}),(\mathrm{D})$, and $(\mathrm{F})]$. 
expression studies confirmed that the cloned AtPIN1 gene corresponded to the PINFORMED locus. As the phenotypes of both pin-formed and Atpin1::En mutants are based on null mutations and a complete loss of the AtPIN1 expression, we conclude that the pinformed and Atpin $1: \because$ En mutants both lack the same component functional in polar auxin transport in Arabidopsis inflorescence axes (13).

The AtPIN1 protein. The predicted AtPIN1 gene product is 622 amino acids long and includes 8 to 12 putative transmembrane segments flanking a central region that is predominantly hydrophilic (Fig. 2C). Similar topologies have been described for proteins that are involved in a wide variety of transmembrane transport processes (14). Database comparisons and screening of libraries with AtPIN1 probes identified several Arabidopsis genes with similarity to AtPIN1 (15). The homologous gene AtPIN2 (also known as EIR1) may encode another catalytic subunit of auxin efflux carrier complexes that performs a similar function in root cells (16). Genes similar in sequence to the AtPIN genes were found in other plant species, even in the evolutionarily distant monocotyledonous species of maize and rice, indicating that AtPIN1 and related genes may be of fundamental importance in plant development (17).

To analyze the function of the AtPIN1 protein in plants, we raised polyclonal antibodies to a portion (amino acid 155 to 408) of recombinant AtPIN1 with an $\mathrm{NH}_{2}$-terminal His $_{6}$ affinity tag. The affinity-purified antibody to AtPIN1 (anti-AtPIN1) identified on protein immunoblots a protein from Arabidopsis microsomes matching the molecular

Fig. 4. AtPIN1 immunolocalization in longitudinal Arabidopsis tissue sections. (A to F) Indirect immunofluorescence analysis by laser scanning confocal microscopy. Stem segments of plants were fixed, sectioned, and incubated with polyclonal anti-AtPIN1 (18). Bound antiAtPIN1 was indirectly visualized with the help of fluorescent (FITC) secondary antibodies (30). The immunofluorescent cells (green-yellow signals) formed continuous vertical cell strands in vascular bundles (A). The AtPIN1 signals are found at the basal end of elongated, parenchymatous xylem cells in the neighborhood of vessel elements, which are distinguished by secondary cell wall thicken-
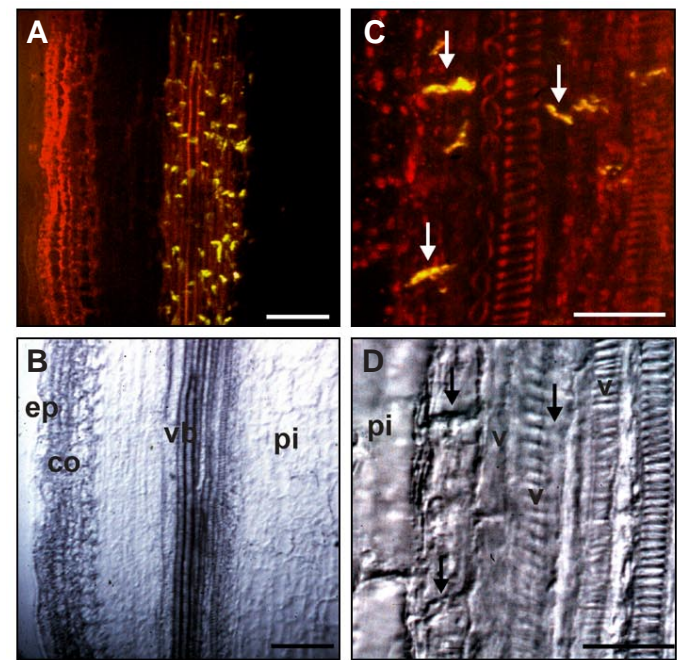

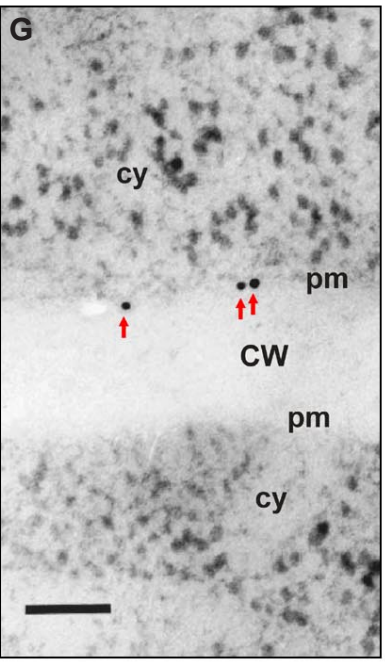

ing structures $(C)$. The red tissue autofluorescence $[(A),(C),(E)$, and $(F)]$ and comparison with the corresponding differential interference contrast (DIC) images [(B) and (D)] facilitated the histological localization of the AtPIN1-specific signals. The arrows point to the AtPIN1-specific fluorescence at the basal end of the xylem cells (C) or to the corresponding positions in the DIC image (D). They also indicate the direction of polar auxin transport in the tissue studied. In (C) two fluorescent signals of three cells forming a vertical cell strand are shown. The upper signal is found at the basal end of the cell extending out of the top of the picture. The cell underneath is fully shown in vertical extension, also fluorescently labeled at its basal end. The fluorescent signal of its basally contacting cell is not shown, because its basal end is out of the picture. A longitudinal hand section of an
Arabidopsis stem is shown in (E). AtPIN1 immunofluorescence is primarily localized to the basal side of the cells extending slightly up the lateral walls. A control with a longitudinal section from the Atpin 1::En134 mutant is shown in (F). No AtPIN1-specific fluorescent signals were detected. (G) Ultrathin tissue sections were incubated with the polyclonal anti-AtPIN 1 and gold-coupled secondary antibodies and examined with an electron microscope $(18,31)$. Gold grains (marked by arrows) were detected only in one membrane of two contacting cells and were absent at the opposite plasma membrane. ep, epidermis; co, cortex; cw, cell wall; cy, cytoplasm; pm, plasma membrane; pi, pith; v, vessel; vb, vascular bundle. Size bars represent $25 \mu \mathrm{m}[(C),(E)$, and (F)], $100 \mu \mathrm{m}(A)$, and $0.1 \mu \mathrm{m}(\mathrm{G})$.

Fig. 5. Analysis of vascular patterning in Atpin $1:: 134$ mutants (32). Inflorescence of a wildtype Columbia Arabidopsis plant (A), an Atpin 1::En134 mutant (B), and a wild-type plant (C), grown in the presence of auxin transport inhibitor NPA $(15 \mu \mathrm{M})$. Cross sections were cut as indicated by arrows in (A), (B), (C). The sections presented were cut just above the first cauline leaf $(1,4,7)$ and directly below the first $(2,5,8)$ and second cauline leaves $(3,6$, 9). Arrows on the cross sections $(5,6,8,9)$ indicate the position of the leaves above. Abnormal xylem proliferation was observed in the inflorescence axis below cauline leaves, adjacent
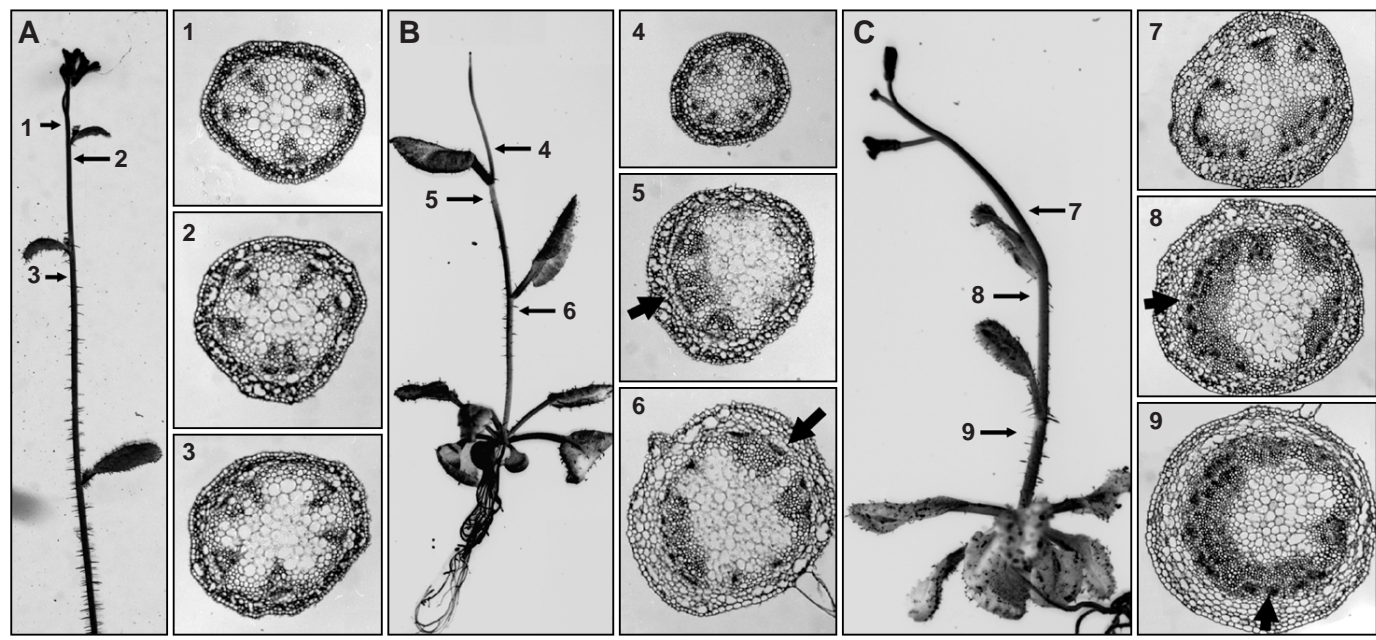

to the leaf attachment site. The diameters of the stem sections are $\sim 1$ to $2 \mathrm{~mm}$. 
mass of $67 \mathrm{kD}$ predicted for AtPIN1 (18).

Polar localization of AtPIN1. To localize the AtPIN1 gene products in situ, we probed cross sections of Arabidopsis inflorescence axes with antisense AtPIN1 RNA and polyclonal anti-AtPIN1. In both cases parenchymatous xylem and cambial cells were labeled (Fig. 3, C to G). Probing longitudinal sections from Arabidopsis inflorescence axes with affinity-purified anti-AtPIN1, we observed labeling at the basal end of elongated parenchymatous xylem cells (Fig. 4, A to E). The basal-apical orientation of the cells was identified with the help of angled razor cuts and residual leaf bases on the excised stem segments. AtPIN1-specific fluorescent signals were primarily located to the basal side of the plasma membrane, with some signal extending beyond the basal side forming a U-shaped fluorescent zone (Fig. 4E). Immunogold labeling and electron microscopy of longitudinal tissue sections revealed gold grains exclusively at the upper membrane of two contacting cells (Fig. 4G). The polar localization of AtPIN1 in these tissues is consistent with the proposed distribution of auxin efflux carriers that mediate shoot-basipetal auxin transport $(2,5,19)$.

Alteration of vascular development. In intact plants, the polar flow of auxin is essential for the formation of spatially organized patterns of vascular tissues (3). We therefore tested whether genetic disruption of the AtPIN1 gene affected vascular pattern formation. In cross sections below the first cauline leaf of Atpin1::134 mutant inflorescence axes, we observed massive radial xylem proliferation in the vascular bundles adjacent to the cauline leaf (Fig. 5). Sections below the second cauline leaf confirmed extensive xylogenesis in the vascular bundles originating from the leaves above. The increase of vascular tissue at positions just below where young auxin-synthesizing leaves were connected to the axial vascular system is consistent with the view that poor basipetal transport in Atpin1 mutants reduces the drainage of auxin from the leaves, leading to enhanced xylem proliferation in the vicinity. Chemical inhibition of polar auxin transport in wild-type plants caused very similar alterations in radial vascular pattern formation (Fig. 5). This indicates that the genetic defect in Atpinl mutants correlates with a defect of cellular auxin efflux at the site of the inhibitor 1-naphthylphthalamic acid (NPA) action in polar auxin transport $(2,20)$. Enhanced vascular tissue differentiation has also been observed in plants that overproduce auxin, supporting a role of auxin gradients in radial vascular pattern formation (21). We suggest that both the mutations in the AtPIN1 locus (Atpin1:: En and pinformed mutants) as well as the chemical inhibition reduced auxin efflux and led to similar alterations in vascular development.

The reduction of polar auxin transport in
Atpin1 mutants and its effects on plant development indicate a role of AtPIN1 in polar auxin transport, most likely in supporting efflux of auxin from the cell. On the basis of the predicted topology of AtPIN1, its homology to carrier proteins, and its polar localization in auxin transport-competent cells, we propose that AtPIN1 might act as a catalytic auxin efflux carrier protein in basipetal auxin transport.

\section{References and Notes}

1. C. Darwin, The Power of Movements in Plants (John Murray, London, 1880); F. W. Went, Rec. Trav. Bot. Neerl. 25, 1 (1928); G. H. van der Weij, ibid. 31, 810 (1934).

2. M. H. M. Goldsmith, Annu. Rev. Plant Physiol. 28, 439 (1977); T. L. Lomax, G. K. Muday, P. H. Rubery, in Plant Hormones, Physiology, Biochemistry and Molecular Biology, P. J. Davies, Ed. (Martinus Nijhoff, Kluwer, Dordrecht, The Netherlands, 1995), Pp. 509530

3. T. Sachs, Pattern Formation in Plant Tissues (Cambridge Univ. Press, Cambridge, 1991); R. Aloni, in Plant Hormones, Physiology, Biochemistry and Molecular Biology, P. J. Davies, Ed. (Martinus Nijhoff, Kluwer, Dordrecht, The Netherlands, 1995), pp. 531546

4. M. Jacobs and P. H. Rubery, Science 241, 346 (1988).

5. M. Jacobs and S. F. Gilbert, ibid. 220, 1297 (1983).

6. K. Okada, J. Ueda, M. K. Komaki, C. J. Bell, Y. Shimura, Plant Cell 3, 677 (1991)

7. S. R. M. Bennett, J. Alvarez, G. Bossinger, D. R. Smyth, Plant J. 8, 505 (1995)

8. G. H. Cardon, M. Frey, H. Saedler, A. Gierl, Plant J. 3, 773 (1993). The heterozygous Atpin1::En134 mutant $\left(M_{1}\right)$ whose $M_{2}$ progeny segregated 3:1 for wild-type and mutant phenotypes, was identified in generation $S_{6}[E$. Wisman, G. H. Cardon, P. Fransz, H. Saedler, Plant Mol. Biol. 37, 989 (1998)]. Backcrosses of heterozygous Atpin 1::En134 plants with wild type expressed the mutant phenotype only in the $F_{2}$ generation.

9. L. Gälweiler et al., data not shown.

10. Crosses between the heterozygous transposon insertional mutants yielded $\sim 25 \%$ mutant phenotypes in the $F_{1}$ generation, indicating allelism. Using En-1- and AtPIN1-specific primers, we amplified the transposonflanking DNA in the Atpin1::En111, Atpin1::En134, and Atpin 1:: En 349 alleles by PCR and then sequenced it. The sequences were identical with AtPIN1 sequences showing independent $E n-1$ insertions.

11. Plant DNA sequences flanking the $5^{\prime}$ end of $E n-1$ in the Atpin 1::En134 allele were cloned by a ligationmediated PCR technique [P. R. Mueller and B. Wold Science 246, 780 (1989); M. Frey, C. Stettner, A. Gierl, Plant J. 13, 717 (1998)] with En-1- and linker-specific oligonucleotides after Csp6 I restriction of genomic DNA and ligation of compatible linker DNA. The isolated flanking DNA was used as a probe to screen a cDNA library, prepared from suspension cells, for homologous clones that were then used to screen a genomic library of $A$. thaliana. The $\lambda$ libraries were prepared from the ecotype Columbia and provided by the Arabidopsis DNA Centre, Cologne. Sequence analysis of the longest AtPIN1 CDNA (2276 base pairs) identified an open reading frame encoding 622 amino acids. An in-frame stop codon located upstream to the first ATC suggested that the CDNA encodes a full-length protein. GenBank accession numbers are as follows: AF089084 (AtPIN1 CDNA) and AF089085 (AtPIN1 genomic DNA).

12. By screening the CIC YAC library \{[F. Creusot et al, Plant J. 8, 763 (1995)]; provided by the Arabidopsis DNA Centre, Cologne\} with a radiolabeled AtPIN1 probe, we identified a contig consisting of the overlapping clones $\mathrm{ClC} 6 \mathrm{H} 1, \mathrm{ClC} 12 \mathrm{G} 10, \mathrm{ClC} 12 \mathrm{H} 9$, and ClC9C4. Physical mapping was performed with the server http://cbil.humgen.upenn.edu/ atgc/physicalmapping.

13. Repeating auxin transport measurements with stem segments, we confirmed the reduction of polar auxin transport in pin-formed mutants $(6,7)$ and found a reduction of polar auxin transport in Atpin1::En134 mutants as well.

14. S. J. Singer, Annu. Rev. Cell Biol. 6, 247 (1990); M. D. Marger und M. H. Saier Jr., Trends Biochem. Sci. 18, 13 (1993); H. Logan, M. Basset, A.-A. Véry, H. Sentenac, Physiol. Plant. 100, 1 (1997).

15. GenBank accession numbers of homologous clones in Arabidopsis thaliana are as follows: ACC002311, AF056026 (EIR1), AF086906 (AtPIN2 CDNA), AF086907 (AtPIN2 genomic DNA), AC002291, AC005560, AB017068, AC004260, ACC003979, AF087016, AF087818, AF087819, AF087820, B61585, T43636, T04468, Z38079, and R84151.

16. C. Luschnig, R. A. Gaxiola, P. Grisafi, G. F. Fink, Genes Dev. 12, 2175 (1998); A. Müller et al., EMBO J. 17, 6903 (1998). AtPIN2 (AF086906) and EIR1 (AF056026) were independently isolated and represent the same genetic locus.

17. GenBank numbers of AtPIN1 homologous rice clones are as follows: AF056027 (REH), D25054, C27713, and C26920.

18. To generate AtPIN1-specific polyclonal antibodies, we ligated a Rsa I fragment of the AtPIN1 cDNA encoding the antigenic peptide of AtPIN1 from amino acid 155 to 408 into the bacterial expression vector PQE-31 (Qiagen). This expression construct encoded a recombinant fusion protein with an $\mathrm{NH}_{2}$-terminal $\mathrm{His}_{6}$ tag. After expression in Escherichia coli SG13009, the recombinant protein was affinity purified on a $\mathrm{Ni}^{2+}$-nitrilotriacetic acid column as described by the Quiaexpressionist manual (Qiagen) and checked by SDS-polyacrylamide gel electrophoresis [U. K. Laemmli, Nature 227, 680 (1970)]. After immunization of rabbits (Eurogentec, Ougrée, Belgium), the polyclonal antiserum was affinity purified against the recombinant AtPIN1 peptide [J. Gu, G. Stephenson, M. J. Iadarola, Biotechniques 17, 257 (1994)] and diluted to a final protein concentration of $0.22 \mathrm{mg} / \mathrm{ml}$. In protein immunoblot analysis the affinity-purified anti-AtPIN1 detected specifically the recombinant AtPIN1 peptide in bacterial extracts as well as a $67-\mathrm{kD}$ protein in microsomal membrane fractions from A. thaliana [R. Zettl, J. Schell, K. Palme, Proc. Natl. Acad. Sci. U.S.A. 91, 689 (1994)]

19. D. A. Morris and A. G. Thomas, J. Exp. Bot. 29, 147 (1978).

20. A. Delbarre, P. Muller, V. Imhoff, J. Guern, Planta 198, 532 (1996)

21. H. J. Klee, R. B. Horsch, M. A. Hinchee, M. B. Hein, N. L. Hoffmann, Genes Dev. 1, 86 (1987); C. Uggla, T. Moritz, G. Sandberg, B. Sundberg, Proc. Natl. Acad. Sci. U.S.A. 93, 9282 (1996).

22. T. Teichmann et al., Eur. J. Biochem. 247, 826 (1997).

23. F. M. Ausubel et al., Current Protocols in Molecular Biology (Green, Wiley, New York, 1993).

24. The $3^{\prime} E n-1$ probe DNA was generated by PCR with the En-1-specific primers En 7631 (5'-TCAGGCTCACATCATGCTAGTCC-3') and En 8141 (5'-GGACCGACGCTCTTATGTTAAAAG-3'). In Southern blot analysis, this PCR product hybridized to the $3^{\prime}$ ends of Xba l-digested En-1 DNA, detecting fragments of 1.98-kb En-1 DNA plus flanking plant DNA.

25. Z. Schwarz-Sommer, A. Gierl, H. Cuypers, P. A. Peterson, H. Saedler, EMBO J. 4, 579 (1985).

26. Single-letter abbreviations for amino acid residues are as follows: A, Ala; C, Cys; D, Asp; E, Glu; F, Phe; G, Gly; H, His; I, Ile; K, Lys; L, Leu; M, Met; N, Asn; P, Pro; Q, Gln; R, Arg; S, Ser; T, Thr; V, Val; W, Trp; and Y, Tyr.

27. J. Kyte and R. F. Doolittle, J. Mol. Biol. 157, 105 (1982).

28. P. Chomczynski and N. Sacchi, Anal. Biochem. 162, 156 (1987). To check for equal RNA loading we rehybridized the Northern blots with ribosomal protein large subunit 4 (RPL4) and ubiquitin carrier (UBC) probes.

29. Segments of inflorescence axes of 3- to 4-week-old A. thaliana ecotype Columbia (grown in a greenhouse at $18^{\circ}$ to $24^{\circ} \mathrm{C}$, with 16 hours of light) were fixed, paraffin embedded, and analyzed by in situ hybridization as described (22), with the following modifications. To generate AtPIN1-specific RNA probes, we inserted the Bgl II-Hind III fragment of the AtPIN1 cDNA (base pairs 602 to 1099) into the Bam HI-, Hind III-cleaved vector pBluescript SK- (Stratagene), 
generating pin23HX. After linearizing pin23HX (Hind III for antisense and Xba I for sense transcription), we performed in vitro transcription and digoxigenin labeling using the DIG RNA Labeling Kit (Boehringer Mannheim). The RNA hybridization was performed overnight at $42^{\circ} \mathrm{C}$ with a probe concentration of 30 ng per $100 \mu \mathrm{l}$. The slides were then washed with $4 \times$ standard saline citrate (SSC) containing $5 \mathrm{mM}$ dithiothreitol (DT T) (10 min, room temperature), $2 \times$ SSC containing $5 \mathrm{mM}$ DT T (30 min, room temperature), and $0.2 \times \mathrm{SSC}$ containing $5 \mathrm{mM}$ DT T $\left(30 \mathrm{~min}, 65^{\circ} \mathrm{C}\right)$. After blocking with $0.5 \%$ blocking agent (Boehringer Mannheim), we detected signals using anti-digoxigenin (1:3000, Boehringer Mannheim) coupled to alkaline phosphatase followed by a nitroblue tetrazolium, brome-chloro-indolyl phosphate staining reaction.

30. Inflorescence axes of 3- to 4-week-old Arabidopsis wild-type and mutant plants (grown in a greenhouse at $18^{\circ}$ to $24^{\circ} \mathrm{C}$, with 16 hours of light) were cut and fixed in ice-cold methanol/acetic acid (3:1). Paraffin embedding, sectioning, and mounting were done as described (22). Antibody incubation and immunohistochemical staining was performed as described [S. Reinold and K. Hahlbrock, Plant Physiol. 112, 131 (1996)], with the following modifications: $8-\mu \mathrm{m}$ cross sections and 30- $\mu \mathrm{m}$ longitudinal sections of inflorescence axes were incubated with affinity-purified anti-AtPIN1 [(18), $4^{\circ} \mathrm{C}$, overnight], diluted 1:100 in buffer [3\% (w/v) milk powder in phosphate-buffered saline (PBS), pH 7.4]. Incubation with secondary antibodies coupled to fluorescein isothiocyanate (FITC) or alkaline phosphatase (Boehringer Mannheim, 1:100) was done at room temperature for 2 to
3 hours. After antibody incubation, washing was performed three times (10 min) with PBS containing $0.2 \%$ Tween 20 . For hand sectioning, stem segments were fixed in $4 \%$ paraformaldehyde, diluted in MTSB (50 mM piperazine ethanesulfonic acid, $5 \mathrm{mM}$ ethylene glycol tetraacetic acid, $5 \mathrm{mM} \mathrm{MgSO}_{4}, \mathrm{pH} 7.0$ ), treated with 2\% Driselase (Sigma, in MTSB, 0.5 hour) and permeabilized with $10 \%$ dimethylsulfoxide and $0.5 \% \mathrm{NP}-40$ (in MTSB, 1 hour). After hand sectioning with razor blades, antibody incubation was performed as described above. Alkaline phosphatase staining reactions were carried out for several hours to overnight, and the results were analyzed microscopically. Fluorescent signal analysis was performed with a confocal laser scanning microscope (Leica DMIRBE, TCS 4D with digital image processing) with a $530 \pm 15 \mathrm{~nm}$ band-pass filter for FITC-specific detection and a $580 \pm 15 \mathrm{~nm}$ band-pass filter for autofluorescence detection. For histological signal localization both images were electronically overlaid resulting in red autofluorescence and green-yellow AtPIN1-specific fluorescence. DIC images were generated to determine the exact cellular signal localization. Controls with preimmune serum and secondary antibodies alone yielded no specific signals. Tissue orientation of the longitudinal stem sections was determined with the help of residual traces of lateral leaves and by cutting stem segments apically and basally with different angles. Polar signal localization was also obvious in cells in which the immunostained cytoplasm was detached from the basal cell wall (9). The AtPIN1 localization results were reproduced by several experiments.
31. Tissue was frozen with an HPM 010 high-pressure instrument (Balzers, Liechtenstein) and processed as described [K. Mendgen, K. Welter, F. Scheffold, G. Knauf-Beiter, in Electron Microscopy of Plant Pathogens, K. Mendgen and K. Lesemann, Eds. (SpringerVerlag, Heidelberg, 1991), pp. 31-42]. Substitution was performed in acetone at $-90^{\circ} \mathrm{C}$, embedding in Unicryl (British Biocell, Cardiff), and polymerization at $4^{\circ} \mathrm{C}$. Ultrathin sections were incubated with primary antibodies [ $1 \%$ preimmune serum or affinitypurified anti-AtPIN1 (18)], diluted 1:10 with buffer $[1 \%(\mathrm{w} / \mathrm{v})$ bovine serum albumin (BSA) and $0.1 \%$ BSA-C, in TBS (10 mM tris(hydroxymethyl)aminomethane-HCL, $150 \mathrm{mM} \mathrm{NaCl}, \mathrm{pH}$ 7.4)], for 3 hours, followed by incubation with a secondary antibody [10 nm gold coupled to goat antibody to rabbit immunoglobulin G (Biotrend, Köln, Germany)], diluted $1: 20$ with buffer, for 1 hour at $20^{\circ} \mathrm{C}$. Sections were stained with uranylate and lead citrate and examined with an Hitachi $\mathrm{H}-7000$ electron microscope.

32. Plants were grown in vitro as described (6), fixed, paraffin-embedded, and deparaffinated as described (22). Cross sections $(10 \mu \mathrm{m})$ of inflorescence axes were analyzed microscopically. Anatomical studies with pin-formed plants gave similar results.

33. We thank P. Huijser for help with the confocal microscopic analysis, H. Vahlenkamp for electron microscopy, C. Koncz for comments on the manuscript, and $\mathrm{H}$. Saedler and J. Schell for continuous support and help. Funded by the European Communities' BIOTECH program and by the Deutsche Forschungsgemeinschaft "Arabidopsis" program.

23 September 1998; accepted 11 November 1998 